\title{
Arylamino-thieno-oxobutanamides under Lawesson's conditions: competition between thienylpyrrole and bithiophene formation
}

\author{
M. Manuela M. Raposo*a, Ana M. B. A. Sampaio a and G. Kirsch ${ }^{\mathrm{b}}$ \\ a Centro de Química, Universidade do Minho, Campus de Gualtar \\ 4710-057 Braga, Portugal \\ b Laboratoire d' Ingénierie Moléculaire et Biochimie Pharmacologique, \\ UFR SciFA/Université de Metz 1, Boulevard Arago, Metz Technopôle, 57078 Metz \\ Cedex 3, France \\ Fax +351 253 678983; e-mail: mfox@quimica.uminho.pt
}

\begin{abstract}
Aryl-2-thienyl-substituted pyrroles 2 and/or 5-arylamino-2,2'-bithiophenes 3 were synthesized by treatment of arylamino-thieno-oxobutanamides 1 with Lawesson's reagent. These in turn were prepared by direct amidation of 4-oxo-(2-thienyl)butanoic acid through $\mathrm{DCC} / \mathrm{BtOH}$ mediated reactions.
\end{abstract}

Keywords: amides, substituent effects, pyrroles, bicyclic compounds, heterocycles.

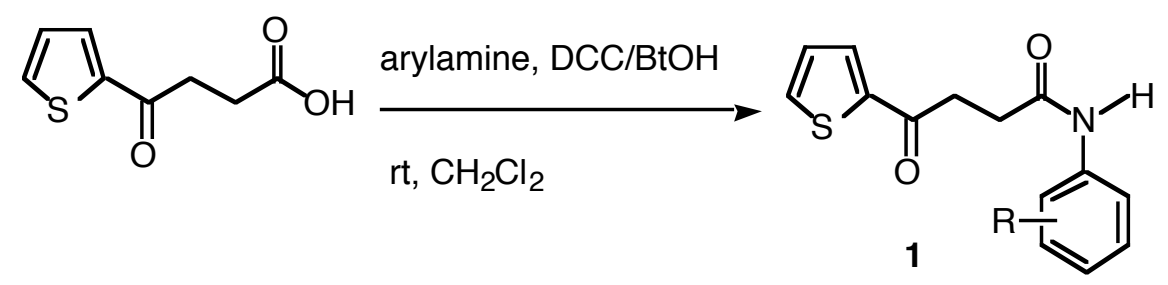

\section{Scheme 1}




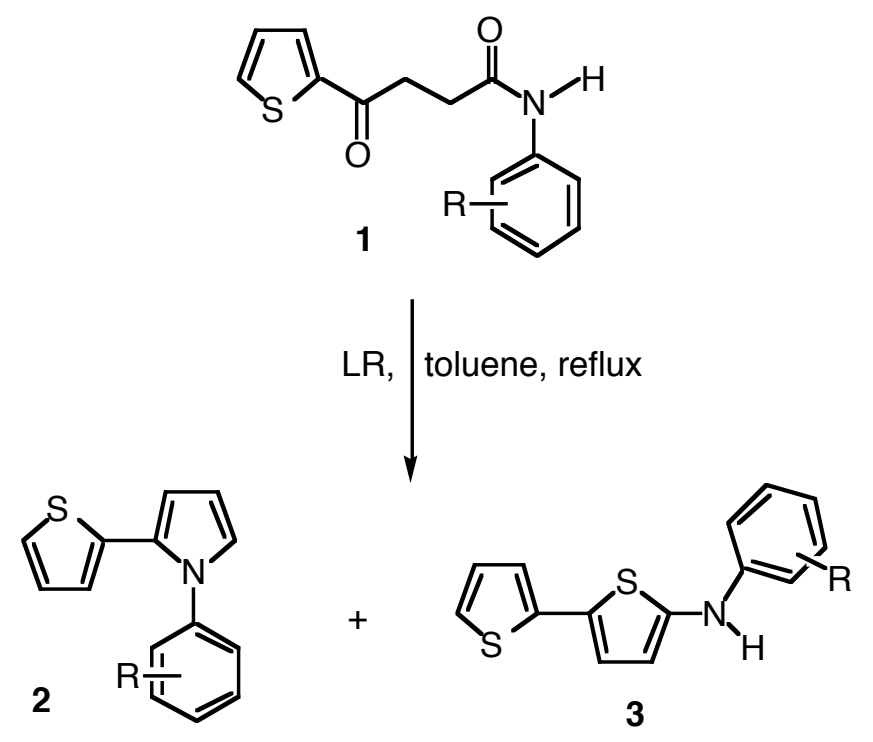

Scheme 2 